\title{
The contribution of brain imaging to the understanding of psychopathy
}

\author{
Jesus Pujol, $\mathrm{MD}^{1}$; Ben J. Harrison, $\mathrm{PhD}^{2}$; Oren Contreras-Rodriguez, $\mathrm{PhD}^{3}$, \\ Narcis Cardoner, $\mathrm{MD}^{4}$
}

\footnotetext{
${ }^{1}$ MRI Research Unit, Department of Radiology, Hospital del Mar, CIBERSAM G21, Barcelona, Spain.

${ }^{2}$ Melbourne Neuropsychiatry Centre, Department of Psychiatry, The University of Melbourne and Melbourne Health, Melbourne, Australia.

${ }^{3}$ Psychiatry Department, Bellvitge University Hospital, Bellvitge Biomedical Research InstituteIDIBELL, CIBERSAM G17, Barcelona, Spain.

${ }^{4}$ Department of Mental Health, Corporació Sanitaria Parc Taulí, Sabadell, and Department of Psychiatry, Autonomous University of Barcelona, Barcelona, Spain.
}

The manuscript contains 4376 words, excluding cites (author-date) in the text and 5432 words, including cites in the text.

Running title: Brain imaging in psychopathy

Funding: This research did not receive any specific grant from funding agencies in the public, commercial, or not-for-profit sectors.

Corresponding author: Dr. Jesus Pujol. MRI Department, Hospital del Mar, Passeig Marítim 25-29. 08003, Barcelona, Spain. Email: 21404jpn@ comb.cat Telephone: +34932212180 Fax: +34932212181 


\section{ABSTRACT}

Psychopathy is a personality type characterized by both callous emotional dysfunction and deviant behavior that affects society in the form of actions that harm others. Historically, researchers have been concerned with seeking data and arguments to support a neurobiological foundation of psychopathy. In the past few years, increasing research has begun to reveal brain alterations putatively underlying the enigmatic psychopathic personality. In this review, we describe the brain anatomical and functional features that characterize psychopathy from a synthesis of available neuroimaging research and discuss how such brain anomalies may account for psychopathic behavior. The results are consistent in showing anatomical alterations involving primarily a ventral system connecting the anterior temporal lobe to anterior and ventral frontal areas, and a dorsal system connecting the medial frontal lobe to the posterior cingulate cortex/precuneus complex and, in turn, to medial structures of the temporal lobe. Functional imaging data indicate that relevant emotional flow breakdown may occur in both these two brain systems and suggest specific mechanisms via which emotion is anomalously integrated into cognition in psychopathic individuals during moral challenge. Directions for future research are delineated emphasizing, for instance, the relevance of further establishing the contribution of early life stress to a learned blockage of emotional self-exposure, and the potential role of androgenic hormones on the development of cortical anomalies. 


\section{INTRODUCTION}

Psychopathy refers to a personality type expressed in the form of emotional callousness, lack of empathy, a grandiose estimation of self, impulsivity and persistent antisocial behavior, among other traits (Hare, 2003). This profile notably overlaps with features defining the antisocial personality disorder (DSM-V, 2013). However, such terms are not synonymous. To meet criteria for psychopathy, an individual must exhibit emotional dysfunction (Blair, 2012). Emotional features such as callousness, lack of empathy and inflated self-appraisal are not necessary to operatively define antisocial personality disorder in the main DSM-V section, which predominantly considers antisocial deviance. However, the alternative trait-based definition section of the DSM-V includes an antisocial personality disorder variant characterized by low anxiety and a bold interpersonal style, which is closer to the traditional view of psychopathy (DSM-V, 2013; Venables et al. 2014). Analogously, the presence of callous-unemotional traits may be used to define a "psychopathic" variant of conduct disorders in children (Patrick, 2014). A historical account of the use of these and related terms (e.g., sociopathy and dissocial disorder) can be found in Kiehl and Hoffman (2011).

The most widely used and validated instrument for the assessment of psychopathy is the interviewbased Psychopathy Checklist-Revised (PCL-R; Hare 2003), which contains distinct affectiveinterpersonal and impulsive-antisocial factors. Various self-report instruments also exist for assessing psychopathy, as well as instruments adapted for children and adolescents (Patrick, 2014). Some inventories are inspired by the PCL-R, while others represent new developments, for instance, the Psychopathic Personality Inventory (Lilienfeld and Andrews 1996) and the Triarchic Psychopathy Measure (Patrick et al. 2009).

Current brain imaging tools offer a unique window to explore the structural and functional bases of normal and deviant behavior. Historically, researchers have been concerned with seeking arguments to 
support a neurobiological foundation of psychopathy, as one of the most enigmatic personality disorders. In the last few years, increasingly abundant data have been provided. Nevertheless, further effort is necessary to integrate the new information. In this review, we describe the anatomical and functional features that characterize the brain of psychopathic individuals from a synthesis of neuroimaging research and discuss how such brain anomalies may account for psychopathic behavior. The available neuroimaging literature on psychopathy, defined in accordance with Hare's concept (Hare, 2003), is analyzed and the review is complemented by a secondary consideration of selected neuroimaging studies assessing young people showing antisocial behavior and callous emotional dysfunction.

\section{BRAIN ANATOMY}

\section{Global brain assessment}

The brain of primary psychopathic individuals (as opposed to patients with psychopathic-like behavior secondary to focal brain damage) does not show any gross anatomical anomalies upon visual inspection. The whole brain volume is similar to the general population in most studies that have provided the measurement (Dolan et al. 2002; Yang et al, 2005; Narayan et al. 2007; Tiihonen et al. 2008; Contreras et al. 2015). Significant brain volume reductions have only rarely been reported (Barkataki et al. 2006). When volumes have been measured for specific lobes using conventional anatomical limits, significant volume reduction was solely observed in the temporal lobe and only a minimal effect was appreciated in the prefrontal lobe (Dolan et al. 2002). psychopathic-like behavior

Within samples of high socioeconomic risk, an association has been reported between the persistence of the cavum septum pellucidum - a fluid-filled space between the two leaflets of the septum - and higher scores of psychopathy (Raine et al. 2010). However, the cavum is similarly prevalent in disruptive behavior disorders in the absence of psychopathy (Raine et al. 2010; Toivonen et al. 2013; 
White et al. 2013,), suggesting that it is mainly a non-specific neuroradiological finding (Saba et al. 2013).

\section{Changes in the content of gray matter}

A large number of studies have focused on measuring the regional content of gray matter. These studies were based on trace delineation of gray/white matter boundaries, voxel-based morphometry and automated measurements of cortical thickness. To a large extent, there is general agreement regarding psychopaths' showing regional cortical reductions in relative gray matter content.

Earlier imaging studies predicted gray matter reductions in the prefrontal lobe of psychopaths (Raine et al. 2000; Yang et al. 2005). Subsequent research has both largely confirmed such a prediction and demonstrated that tissue alteration extends to other brain locations (Laakso et al. 2001; Laakso et al. 2002; Narayan et al. 2007; de Oliveira-Souza et al. 2008; Müller et al. 2008; Tiihonen et al. 2008; Yang et al. 2009a, b, 2010; Boccardi et al. 2011; Raine et al. 2011; Sato et al. 2011; Ermer et al. 2012; Gregory et al. 2012; Ly et al. 2012; Bertsch et al. 2013; Boccardi et al. 2013; Kolla et al. 2014; Kumari et al. 2014; Contreras-Rodríguez et al. 2015; Walters et al. 2015; Jiang et al. 2016), as summarized in Table 1. Although the number of reported brain areas indicates a tendency for changes to affect the cortex globally, gray matter volume reduction is particularly consistent across studies in (i) the rostral temporal lobe and the rostral and ventral frontal lobe including the ventral-medial and orbitofrontal cortex; (ii) the dorsal aspect of the brain medial wall involving a dorsal/medial frontal area extending to the anterior cingulate cortex and the posterior cingulate cortex/precuneus; (iii) the posterior parahippocampal gyri/medial visual cortex; and (iv) the sensorimotor cortex. Figure 1 provides an overall depiction of this consistent pattern of gray matter volume reduction in psychopaths.

The set of cortical regions shown in Figure 1 represent a combination of neocortical and paralimbic areas. Although the involvement of other (limbic) elements has frequently been emphasized in 
psychopathy, only a few studies have actually detected significant volume reduction in structures such as the amygdala, hippocampus and insula, as indicated in Table 1. Moreover, some analyses specifically targeting the individual limbic structures using manual tracing failed to find the predicted volume reduction in the amygdala (Barkataki et al. 2006; Boccardi et al. 2011), hippocampus (Barkataki et al. 2006; Boccardi et al. 2010; Raine et al. 2004) and anterior cingulate cortex (Glenn et al. 2010a). However, the limbic/paralimbic system as a whole (integrated using latent-variable modeling) does appear to be a major contributor to psychopathy (Baskin-Sommers et al. 2016).

A number of meta-analyses have been conducted in attempt to summarize common findings across studies of regional brain volumes. However, it is relevant to note that none have focused specifically on psychopathy. Existing meta-analyses have instead broadly pooled finding from studies of antisocial behavior (Aoki et al. 2014; Yang and Raine, 2009), interpersonal violence (Lamsma et al. 2017), oppositional defiant disorder (Noordermeer et al. 2016) and conduct problems (Rogers et al. 2016). Although these analyses have mapped regional volume reductions consistent with the emphasis of our review (Figure 1), the frequency and extent of such alterations has notably been more discrete. It has been argued that the phenomenological and etiological heterogeneity of antisocial behavior, in particular, as well as methodological differences between studies, may explain the limited results of current meta-analytic studies (Lamsma et al. 2017).

In children and adolescents with psychopathic traits, research has demonstrated gray matter changes distributed in regions notably reminiscent of adult psychopathic patterns (De Brito et al. 2009; Ermer et al. 2013; Fairchild et al. 2013; Cope et al. 2014). However, such studies have produced mixed findings as to the direction of the alteration. Interestingly, young individuals (mean age of 12 years) show a gray matter volume increase (De Brito et al. 2009) associated with psychopathic traits, whereas in older individuals (mean age of 17 years), psychopathic traits are instead associated with a gray matter volume decrease in both males (Ermer et al. 2013) and females (Cope et al. 2014).). One study in female adolescents showed a mixed brain pattern of positive and negative correlations 
(Fairchild et al. 2013). Taking both young and adult studies together, alterations in gray matter volume in psychopathy may be hypothesized to evolve dynamically throughout life from a relative gray matter increase to a relative decrease.

In support of a developmental dynamic basis of brain tissue alterations in psychopathy, one study reported a significant association of childhood physical abuse with gray matter volume reduction in the temporal pole of adult psychopaths (Kolla et al. 2014). Child abuse was also associated with reduced fronto-temporal cortical thickness predicting antisocial behavior in adolescents (Busso et al. 2017). In another study, the combination of relatively lower cortical volumes and higher volumes in subcortical regions was found to partially mediate the relation between adverse life events and antisocial behavior in a sample of 1,741 adolescents (Mackey et al. 2017). At age 25 years, a voxelbased morphometry analysis demonstrated the association of early life poverty with gray matter volume reduction precisely in the ventral-medial frontal cortex (Holz et al. 2015). Symptoms related to early-onset cumulative adversity have similarly been associated with reduced gray matter volumes in persistent delinquent youths (Raine et al. 2003).

\section{Changes in the content of white matter}

Despite consistency across studies, the extent to which reductions of gray matter volumes in adult psychopaths described above express true gray matter loss (i.e., atrophy) is not obvious. Indeed, results from white matter analyses suggest that white matter increases may contribute to relative reductions of gray matter measurements in the absence of relevant brain volume changes.

When results have been provided, white matter volume changes have generally paralleled the findings of gray matter changes in the opposite direction, with volume increases in global, prefrontal and corpus callosum white matter correlating with psychopathy scores (Raine et al. 2003; Yang et al. 2005). Larger volumes have also been demonstrated for basal ganglia elements with a very high content of white matter (Barkataki et al. 2006; Glenn et al. 2010b; Pujara et al. 2014). 
A similar tendency has also been observed in disorders overlapping with psychopathy. In persistently violent offenders with antisocial personality disorder significantly larger white matter volumes were observed in broadly distributed brain regions grossly coinciding with areas of gray matter volume reduction (Tiihonen et al. 2008). In young males with psychopathic traits, a mixed pattern of changes has been reported combining both increases and decreases in regional white matter volume (De Brito et al. 2011).

It has been argued that the relative increase of white matter in psychopaths may be related to nonoptimal brain remodeling (deficient axonal pruning), resulting in excessive anatomical connections (Raine et al. 2003). However, alternatively, we suggest here that larger white matter volumes in psychopathy may also relate to significantly accelerated myelination. It is important to note that white matter segments in conventional (T1-weighted) anatomical MRI scans correspond to myelinated white matter (Paus et al. 2001). Myelination is an active process throughout life (Yakovlev \& LeCours, 1967; Pujol et al. 1993; Narayan et al. 2007), which is physiologically accelerated in early postnatal years and during adolescence (Paus et al. 2001; Pujol et al. 2006), and enhanced by repetitive use or skill learning (McKenzie et al. 2014; Pujol et al. 2016). Pathological acceleration of myelination has been suggested, for example, in melancholic depression (Soriano-Mas et al. 2011), childhood obesity (Ou et al. 2015), heavy cannabis use (Matochik et al. 2005) and pathological lying (Yang et al. 2005).

To summarize, measurable changes in gray and white matter regional tissue content can be detected in the brain of psychopaths in the absence of changes of total brain volume. This overall pattern of findings argues against gray matter atrophy as a sole explanation for gray matter volume reductions in psychopaths. We propose that accelerated myelination may be one contributing factor, in that it affects image tissue segmentation by displacing the boundary between white and gray matter.

\section{Changes in the structure of white matter pathways}


Potential alterations in the structure of white matter pathways have been investigated using diffusion tensor imaging (DTI). The common measurement across all studies is fractional anisotropy (FA), which quantifies the degree of structural maturation of white matter by estimating water diffusivity along tracts (Lebel et al. 2012). DTI studies of psychopathic populations coincide in showing FA reductions mostly involving frontal lobe connections (Craig et al. 2009; Motzkin et al. 2011; Sundram et al. 2012; Hoppenbrouwers et al. 2013; Sethi et al. 2015; Wolf et al. 2015; Jiang et al. 2017b).

Alterations in the ventral connections between the frontal lobe and the temporal lobe would appear to be a solid finding, which mostly implicate the uncinate fasciculus (Craig et al. 2009; Motzkin et al. 2011; Sundram et al. 2012; Hoppenbrouwers et al. 2013; Wolf et al. 2015; Jiang et al. 2017b). Significant FA reductions have also been identified in dorsal pathways connecting the frontal lobe with the parietal lobe (Sundram et al. 2012; Sethi et al. 2015; Jiang et al. 2017b). Interestingly, the cingulum is altered both ventrally and dorsally, with FA reductions detected in the segment connecting the posterior cingulate cortex with the medial temporal lobe and the segment connecting the posterior cingulate cortex with the frontal lobe (Sethi et al. 2015). Frontal lobe structural connectivity alterations in psychopaths therefore seem to implicate dorsal and ventral bundles that connect brain areas that broadly demonstrate gray matter volume reductions (summarized in Figure 1). However, frontal lobe connectivity changes are not limited to the anterior-posterior direction, as reduced FA has also been demonstrated in the genu of corpus callosum (transverse connections) (Sundram et al. 2012) and in frontal-basal ganglia connections (Sundram et al. 2012; Hoppenbrouwers et al. 2013).

Reductions in FA can be interpreted as expressing a maturation delay in late maturing bundles (Sethi et al. 2015). Nevertheless, accelerated, as opposed to delayed, maturation may better account for the majority of pathway alterations in psychopaths. Indeed, the increase in FA from normal childhood to adulthood reaches a peak between 20 and 40 years of age, and subsequently decreases (Lebel et al. 2012). Accordingly, from early adulthood, the normal physiological evolution of FA is one of progressive reduction, presumably reflecting increased white matter structural complexity 
accompanying brain maturation (Douaud et al. 2011; Jones et al. 2013). In DTI studies of psychopathy, the mean age of adult samples has broadly coincided with the FA peak, or with the beginning of FA decreases (age range across studies, 30 to 40 years), with the sole exception of one study (Jiang et al. 2017b). Thus, within this age range, reduced FA is better explained by accelerated maturation, or psychopaths reaching FA maturity earlier than what is normally observed. Interestingly, in the DTI study featuring the youngest population (mean age 23 years), a combination of FA decreases (predominant) and increases was reported (Jiang et al. 2017b).

DTI analyses in younger populations with callous-unemotional traits have provided mixed results, with different studies reporting higher, lower or no differences in FA versus healthy controls for diverse white-matter tracts (see Waller et al. (217) for a review). These findings offer further support for the proposal that abnormally accelerated white matter maturation contributes to the nature of anatomical changes in psychopathy and callousness. FA increase will be identified in youths, compared with typically developing controls, at ages prior to the FA age-related peak (the ascending part of the curve) for a given bundle, and FA reduction in older individuals closer to the age at which FA begins to decrease (Waller et al. 217). Here too, early life stress could play a significant role. In one study, adults with life-time exposure to parental abuse showed FA reduction in the hippocampal extension of the cingulum bundle, the fornix and the arcuate fasciculus (Choi et al. 2009).

\section{BRAIN FUCTION}

\section{Functional connectivity}

Functional connectivity is considered a measurement of activity synchrony between brain regions sharing functional properties (Biswal et al. 1995). In antisocial offenders, the assessment of functional connectivity changes using whole-brain measures has provided evidence of both reduced functional integration and segregation in the organization of large-scale brain networks (Jiang et al. 2016a). In global terms, such findings may be interpreted as reflecting deficient brain functional maturation (Fair 
et al. 2009; Pujol et al. 2016). The integration and segregation of large-scale brain networks is a lifetime process that is especially active during adolescence (Sherman et al. 2014). Thus, the hypothetical acceleration of white matter maturation does not seem to imply a more efficient coupling among late maturing networks in the case of psychopaths (i.e., maturation may be faster but deficient).

As in the case of other imaging alterations, global brain changes in functional connectivity have been observed in association with changes that are particularly prominent in specific brain systems. Once again, the frontal cortex is the structure that shows the most relevant connectivity alterations in psychopaths. Some evidence indicates reduced functional connectivity between ventral frontal areas and the anterior temporal lobe and amygdala at rest (Motzkin et al. 2011) and during emotional stimulation (Decety et al. 2013a; Yoder et al. 2015; Volman et al. 2016). Other studies have demonstrated reduced functional connectivity of the dorsal frontal cortex (and anterior cingulate cortex) with several limbic-paralimbic structures (Ly et al. 2012; Pujol et al. 2012; Contreras et al. 2015; Philippi et al. 2015) and, particularly, with the posterior cingulate cortex/precuneus complex (Pujol et al. 2012; Contreras et al. 2015; Philippi et al. 2015).

In addition to long-distance connectivity reduction, psychopaths appear to display higher functional connectivity within the dorsal aspect of the frontal lobes at rest (Contreras et al. 2015), and between dorsal frontal areas and the striatum during reward expectancy (Geurts et al. 2016). Higher frontal cortex connectivity was associated with more severe lifestyle/antisocial traits (Hare Factor 2) in the study carried out by Philippi et al. (2015). In general agreement with such functional connectivity findings, studies of structural connectivity (structural covariance) estimated from cortical thickness measurements, also implicates the superior frontal cortex as a relevant connectivity hub in psychopaths (Yang et al. 2012). Reduced functional connectivity also seems to combine with increased connectivity in antisocial personality disorder (Tang et al. 2016). 


\section{Brain activation}

\section{Brain response to emotional stimuli}

A number of studies have examined how psychopaths respond to emotionally provocative stimuli, including emotional faces (Deeley et al. 2006; Decety et al. 2013b, 2014; Contreras et al. 2014; Hyde et al. 2014; Mier et al. 2014; Pera-Guardiola et al. 2016; Volman et al. 2016), unpleasant pictures (Müller et al. 2003; Decety et al. 2013b; Harenski et al. 2014; Sitaram et al. 2014), emotion-laden scenes (Decety et al. 2013b, 2015; Meffert 2013) and emotional words (Contreras et al. 2014). Collectively, these studies indicate that the neural processing of emotional stimuli is altered in psychopaths. However, depending on the nature of the experiment, studies have reported either attenuated (Deeley et al. 2006; Harenski et al. 2014; Hyde et al. 2014; Mier et al. 2014; Volman et al. 2016) or enhanced (Intratot et al. 1997; Contreras et al. 2014) or indeed a combination of response changes (Decety et al. 2013a, b, 2014, 2015) in different elements of the "emotion processing" network. Relevantly, enhanced brain response has been reported for visual sensory areas (Contreras $e t$ al. 2014), association sensory cortex (Decety et al. 2013b; Contreras et al. 2014), insula (Decety et al. 2013b, 2014), anterior cingulate cortex (Decety et al. 2013b), basal ganglia (Decety et al. 2013a, b) and frontal (predominantly dorsal) areas (Contreras et al. 2014; Decety et al. 2013b). Thus, the psychopath's brain is not necessarily "unemotional" in terms of its response to emotional stimulation, which may be enhanced at some processing stages. Nevertheless, a disruption of the emotional flow occurs, perhaps in the transition of processing from temporal lobe structures to the ventral prefrontal cortex. Indeed, the amygdala (Decety et al. 2013a, 2014; Contreras et al. 2014; Harenski et al. 2014; Hyde et al. 2014; Mier et al. 2014) and the ventral prefrontal cortex (Decety et al. 2013b, 2014) both show only a modest or attenuated response to emotional stimuli in psychopaths, and the normal functional coupling between both elements appear to be reduced during task performance (Decety et al. 2013a; Contreras et al. 2014; Volman et al. 2016).

Brain response to aversively conditioned stimuli (e.g., with pain) has also been tested in psychopaths. Once again, the results have been divergent, with evidence for both attenuated (Veit et al. 2002; 
Larson et al. 2013; Decety et al. 2014) and enhanced (Schneider et al. 2000; Schultz et al. 2016) brain activations, which further suggests that the experimental context is critical in determining the magnitude and direction of the response. Attention seems to be a relevant factor that may explain some apparent discrepancies. For example, compared with control subjects, psychopaths showed lower right amygdala and higher left frontal response to a short (200 ms) exposure to a painconditioned stimulus when attention was engaged in a neutral task (Larson et al. 2013). By contrast, long exposure $(8 \mathrm{~s})$ to a pain-conditioned complex image generated a greater response, in this case in the left amygdala and in areas processing visual stimuli features (Schultz et al. 2016).

There is also evidence relating psychopathy to altered responses to incentive stimulation. Specifically, psychopathy has been associated with lower basal ganglia activation related to monetary loss (Pujara et al. 2014), lower medial frontal activation during reward anticipation (Veroude et al. 2016) and lower anterior cingulate cortex activation in response to reward uncertainty (Prehn et al. 2013), while increased activation has been observed in the posterior cingulate cortex and anterior insula during the task reversal phase (Gregory et al. 2015). Also, higher psychopathy scores have been associated with reduced response to drug abuse-related pictures in the basal ganglia and connected brain structures (Cope et al. 2014)

\section{Brain activity during moral challenge}

Neuroimaging research has demonstrated the involvement of a well-defined brain network in the mediation of moral judgment in the normal population. This network overlaps with the so-called default mode network connecting the medial frontal cortex, the posterior cingulate cortex and the angular gyri (Greene et al. 2001), but also medial structures of the temporal lobe and upper brainstem (Harrison et al. 2008; Pujol et al. 2012). In functional MRI studies, psychopaths required to make a judgment in a moral dilemma situation (Figure 2) have consistently shown deficient activation in the medial frontal and posterior cingulate cortex (Glenn et al. 2009; Harenski et al. 2010; Veit et al. 2010; Pujol et al. 2012; Yoder et al. 2015) and, remarkably, in the hippocampus and parahippocampal gyrus 
extending to the periaqueductal gray (Pujol et al. 2012) and amygdala (Glenn et al. 2009; Pujol et al. 2012; Marsh et al. 2014; Yoder et al. 2015). Such experiments may therefore show the inappropriate use of a network that both mediates attention to self as an agent and has access to autobiographical storage (Moll et al. 2007; Bado et al. 2014; Leech et al. 2014). Consistent with this view, criminal psychopaths precisely showed lower activity in the posterior (and anterior) cingulate cortex, parahippocampal gyrus, hippocampus and amygdala during the performance of an affective memory task (Kiehl et al. 2001).

A functional "breakdown" in the brain network subserving moral judgment may also extend to neutral situations unrelated to the moral context. Functional MRI signal reduction or deactivation typically observed in the default mode network during conventional cognitive tasks is deficient in psychopaths (Pujol et al. 2012; Juárez et al. 2013; Freeman et al. 2015). Moreover, the anterior and posterior elements of the default mode network appeared to be significantly uncoupled during the resting state in functional connectivity analyses (Pujol et al. 2012). Therefore, the network abnormally responding during moral challenge would also seem to be primarily altered. This idea is consistent with the proposal that attentional deficits in psychopaths are not limited to situations of moral conflict, but extend more generally to other attentional domains (Newman et al. 2010, 2016; Aharoni et al. 2013; Rodman et al. 2016).

The arousal generated by a moral challenge in psychopaths appears to depend on how the self is taken as a reference. While watching morally-laden scenes, psychopaths showed higher frontal activation when identifying the emotional state of the victim and lower frontal activation when identifying the emotional state of the predator (Decety et al. 2015). However, other data suggest that if the psychopath is forced to feel like the predator - as opposed to simply having to identify the predator's emotional state- such a response attenuation may be less evident (Sommer et al. 2010; Decety et al. 2013; Meffert et al. 2013), further suggesting an attentional selection bias (Newman et al. 2010, 2016). 
In brief, while psychopaths are reactive to different forms of emotional stimulation, emotional processing may be incomplete with poor temporal lobe transmission of emotional flow to the ventral frontal system. Also, moral challenge experiments have revealed the inappropriate use of a dorsal network mediating attention to our inner emotional world.

In addition to functional imaging of evoked brain activation, other studies have assessed brain function based on a variety of metabolic parameters. Regional glucose metabolism and cerebral blood flow have generally been reported to be lower in psychopaths, particularly in frontal and temporal areas (Volkow et al. 1995; Raine et al. 1997; Soderstrom et al. 2002). One study reported lower levels of monoamine oxidase-A, an enzyme that regulates neurotransmitters, in the orbitofrontal cortex and ventral striatum in offenders with high psychopathic traits (Kolla et al. 2015). Other authors have reported a positive correlation between striatal serotonin 1B receptor binding and the level of psychopathy (da Cunha-Bang et al. 2016).

\section{GENERAL IMPLICATIONS}

In this review, we provide a synthesis of available neuroimaging research directly concerning to psychopathy. A variety of imaging methods has been used to date to provide distinct perspectives of brain structure and function. There are notable differences across the findings of existing studies, which is likely to reflect important differences in study methodology, but may also reflect the underlying biological heterogeneity of psychopathy. Nevertheless, most studies coincide in suggesting that the brain of psychopaths differs notably from the typical brain in terms of both anatomy and function. There is a tendency for changes to affect the brain globally, but variations from the normal pattern are particularly evident in a number of functionally related brain structures. One system includes the rostral aspect of both frontal and temporal lobes, which subcortically report to the ventral striatum and anterior hippocampus/amygdala, respectively. Although this system is involved in a vast 
variety of processes, in the context of psychopathy, we emphasize its role in conveying emotional input to motivated actions (Simpson \& Balsam, 2016). The second system combines the medial frontal (and anterior cingulate) cortex with the posterior cingulate cortex/precuneus, core elements of the default mode network, which are critical in focusing attention on self and accessing autobiographical storage (Bado et al. 2014; Leech et al. 2014). This dorsal system is connected to caudal temporal lobe structures also altered in psychopathy. Relevant changes have been identified in the parahippocampus/posterior hippocampus and visual areas involved in the processing of sensory stimulation in general, but also relevant for the storage of significant autobiographical events (Jeong et al. 2015). In addition, alterations have also been reported involving the sensorimotor cortex, which is the primary representation of our bodies.

Functional data suggest that emotionally evocative stimuli are indeed capable of activating the brain and even generating excessive responses in some (mostly dorsal) emotion-relevant brain areas in psychopaths. However, the emotional processing flow may appear to be disrupted in the transition from the temporal lobe to ventral frontal areas, with the consequent failure to integrate emotion into cognition and subsequent decisions, as often proposed (Kiehl et al. 2001; Raine et al. 2006; Blair et al. 2007, 2016; Moll et al. 2008; Contreras et al. 2014). The alteration in emotional processing resulting from such ventral temporal-frontal blockage may be sufficient to account for psychopathic behavior if taken to the extreme. Indeed, in frontotemporal dementia and after focal damage of rostral frontotemporal areas, the presence of psychopathic-like behavior is not exceptional (Anderson et al. 1999; Brower et al. 2001; Koenigs et al. 2007; Moll et al. 2007; Diehl-Schmid et al. 2013; Birkhoff et al. 2016; Darby et al. 2018).

Nevertheless, imaging data indicate that emotional processing blockage may also occur as a result of the abnormal functioning of a dorsal brain system. Probably the most consistent finding in functional imaging research in the context of adult psychopathy is the alteration of the network involved in the mediation of moral judgment overlapping with the default mode network. The normal activation of 
this network serves to focus attention on the self as an agent and thus (as we propose) exposing the individual to be aroused (or "touched") from emotional (positive or negative) memories stored in temporal lobe medial structures. Activation of the default mode network during moral conflict is certainly abnormal in psychopaths (Glenn et al. 2009; Harenski et al. 2010; Veit et al. 2010; Pujol et al. 2012; Yoder et al. 2015), which concurs with a similarly poor activation of key memory structures such as the parahippocampal gyrus, hippocampus and amygdala (Glenn et al. 2009; Pujol et al. 2012; Marsh et al. 2014; Yoder et al. 2015).

All in all, a failure to integrate emotion into cognition would appear to result from at least two complementary breakdowns; bottom-up disruption of the emotional flow in the ventral frontotemporal system and a top-down blockage of emotional self-exposure in the dorsal network mediating moral judgment.

\section{FUTURE DIRECTIONS}

In the present review, we have focused on how current neuroimaging research may contribute to a better understanding of pathophysiological mechanisms leading to psychopathic behavior. Nevertheless, another question is whether neuroimaging can provide clues as to its etiology? We would emphasize three potential causal factors deserving future research, in addition to genetic predisposition, which always plays a significant role in complex behavioral disorders.

As discussed earlier, one of the factors that potentially contributes to the development of brain pathology in psychopaths is life-time stress, which may well accelerate brain maturation. Life-time stress could indeed contribute to regional gray matter volume reduction through excessive neural activity leading to subsequent atrophy (a "burnout" effect) or by increasing myelinated white matter with an apparent reduction of the gray matter tissue segment, or both. Future analyses may specifically focus on determining the life-time evolution of cortical white matter content. Additionally, it may be 
valuable in this context to test the hypothesis of accelerated brain maturation from a functional perspective, by assessing both brain activity and functional network connectivity in children and adolescents with psychopathic traits.

Androgens have a relevant effect on brain shaping. Critical periods include the prenatal androgenization of the brain and androgen activation during adolescence (Arnold et al.1984; Sato et al. 2008). The male and female brain differs, in part, due to androgen effects (Heany et al. 2016) and antisocial behavior is substantially more frequent in males (Yildirim et al. 2012). Thus, anomalies in developmental androgenic brain modelling may increase the predisposition to psychopathy (Yildirim et al. 2012). Relevantly, the effects of prolonged high-dose administration of androgenic steroids on brain anatomy are largely reminiscent of gray matter alteration patterns in psychopaths showing reduced cortical thickness in rostral frontotemporal areas, the medial frontal cortex, the posterior cingulate cortex/precuneus and visual areas (Figure 3) (Bjørnebekk et al. 2017).

Finally, the results from some analyses suggest that the described brain alterations could show distinct and opposite patterns of association with both affective disturbances and antisocial behavior. Indeed, some brain alterations are reported to be associated with more affective disturbances (Hare Factor 1) and less antisocial behavior (Hare Factor 2), including reductions in gray matter volume (Contreras et al. 2015), altered functional connectivity in large-scale cortical networks (Philippi et al. 2015) and amygdala reactivity (Hyde at al. 2014). A recent study further indicates that the severity of antisocial behavior is associated with larger prefrontal and striatal subregion volumes and higher functional connectivity between several areas of the prefrontal cortex (Korponay et al. 2017a, b). Future research on this issue is therefore of great interest to ascertain whether the described alterations in brain structure and function in psychopaths necessarily predispose them to crime. Interestingly, there are behavioral data indicating that antisocial behavior, as measured in Hare Factor 2, is better explained by poorer cognitive functioning (Baskin-Sommers et al. 2015). 


\section{CONCLUSIONS}

This review has sought to provide a consolidated perspective on the contribution of brain imaging to understanding of psychopathy. The brain of psychopaths differs from the typical brain in terms of both anatomy and function. Anatomical alterations involve primarily a ventral system connecting the anterior temporal lobe to anterior and ventral frontal areas, and a dorsal system connecting the medial frontal lobe to the posterior cingulate cortex/precuneus complex and, in turn, to medial structures of the temporal lobe. Functional imaging data indicate that a significant disruption or 'breakdown' in the flow of emotional information processing may occur in both these two brain systems and suggest specific mechanisms via which emotion is anomalously integrated into cognition in psychopathic individuals during moral challenge. To this end, broader reviews are of interest comparing the results from different fields including, for instance, EEG, genetics, neurochemistry and neuropsychology. 


\section{Acknowledgements}

We thank Dr. Laura Blanco-Hinojo for her valuable comments. Dr. Oren Contreras-Rodríguez thanks the Instituto de Salud Carlos III for the Sara Borrell Contract (CD14/00246).

\section{Funding}

This research did not receive any specific grant from funding agencies in the public, commercial, or not-for-profit sectors.

\section{Conflicts of interest}

None. 


\section{REFERENCES}

Aharoni E, Vincent GM, Harenski CL, Calhoun VD, Sinnott-Armstrong W, Gazzaniga MS, Kiehl KA (2013). Neuroprediction of future rearrest. Proceedings of the National Academy of Sciences of the USA 110, 6223-6228.

American Psychiatric Association (2013). Diagnostic and Statistical Manual of Mental Disorders, Fifth Edition. American Psychiatric Association, Arlington, VA.

Anderson SW, Bechara A, Damasio H, Tranel D, Damasio AR (1999). Impairment of social and moral behavior related to early damage in human prefrontal cortex. Nature Neuroscience $\mathbf{2}$, 10321037.

Aoki Y, Inokuchi R, Nakao T, Yamasue H (2014). Neural bases of antisocial behavior: a voxelbased meta-analysis. Soc Cogn Affect Neurosci 9, 1223-1231.

Arnold AP, Gorski RA (1984). Gonadal steroid induction of structural sex differences in the central nervous system. Annual Review of Neuroscience 7, 413-442.

Bado P, Engel A, de Oliveira-Souza R, Bramati IE, Paiva FF, Basilio R, Sato JR, Tovar-Moll F, Moll J (2014). Functional dissociation of ventral frontal and dorsomedial default mode network components during resting state and emotional autobiographical recall. Human Brain Mapping 35, 3302-3313.

Barkataki I, Kumari V, Das M, Taylor P, Sharma T (2006). Volumetric structural brain abnormalities in men with schizophrenia or antisocial personality disorder. Behavioural Brain Research 169, 239-247.

Baskin-Sommers AR, Brazil IA, Ryan J, Kohlenberg NJ, Neumann CS, Newman JP (2015). Mapping the association of global executive functioning onto diverse measures of psychopathic traits. Personality Disorders 6, 336-346.

Baskin-Sommers AR, Neumann CS, Cope LM, Kiehl KA (2016). Latent-variable modeling of brain gray-matter volume and psychopathy in incarcerated offenders. Journal of Abnormal Psychology 125, 811-817. 
Bertsch K, Grothe M, Prehn K, Vohs K, Berger C, Hauenstein K, Keiper P, Domes G, Teipel S, Herpertz SC (2013). Brain volumes differ between diagnostic groups of violent criminal offenders. European Archives of Psychiatry and Clinical Neuroscience 263, 593-606.

Birkhoff JM, Garberi C, Re L (2016). The behavioral variant of frontotemporal dementia: An analysis of the literature and a case report. International Journal of Law and Psychiatry 47, 157163.

Biswal B, Yetkin FZ, Haughton VM, Hyde JS (1995). Functional connectivity in the motor cortex of resting human brain using echo-planar MRI. Magnetic Resonance in Medicine 34, 537-541.

Bjørnebekk A, Walhovd KB, Jørstad ML, Due-Tønnessen P, Hullstein IR, Fjell AM (2017). Structural brain imaging of long-term anabolic-androgenic steroid users and nonusing weightlifters. Biological Psychiatry 82, 294-302.

Blair RJ (2007). The amygdala and ventromedial prefrontal cortex in morality and psychopathy. Trends in Cognitive Science 11, 387-392.

Blair RJ (2012). Cortical thinning and functional connectivity in psychopathy. The American Journal of Psychiatry 169, 684-687.

Blair RJ, Veroude K, Buitelaar JK (2016). Neuro-cognitive system dysfunction and symptom sets: A review of fMRI studies in youth with conduct problems. Neuroscience \& Biobehavioral Reviews [Epub ahead of print] doi, 0.1016/j.neubiorev.2016.10.022.

Boccardi M, Bocchetta M, Aronen HJ, Repo-Tiihonen E, Vaurio O, Thompson PM, Tiihonen J, Frisoni GB (2013). Atypical nucleus accumbens morphology in psychopathy: another limbic piece in the puzzle. International Journal of Law and Psychiatry 36, 157-167.

\section{Boccardi M, Frisoni GB, Hare RD, Cavedo E, Najt P, Pievani M, Rasser PE, Laakso MP,} Aronen HJ, Repo-Tiihonen E, Vaurio O, Thompson PM, Tiihonen J (2011). Cortex and amygdala morphology in psychopathy. Psychiatry Research 193, 85-92.

Boccardi M, Ganzola R, Rossi R, Sabattoli F, Laakso MP, Repo-Tiihonen E, Vaurio O, Könönen M, Aronen HJ, Thompson PM, Frisoni GB, Tiihonen J (2010). Abnormal hippocampal shape in offenders with psychopathy. Human Brain Mapping 31, 438-447. 
Brower MC, Price BH (2001). Neuropsychiatry of frontal lobe dysfunction in violent and criminal behaviour: a critical review. Journal of Neurology, Neurosurgery, and Psychiatry 71, 720-726.

Busso DS, McLaughlin KA, Brueck S, Peverill M, Gold AL, Sheridan MA (2017). Child Abuse, Neural Structure, and Adolescent Psychopathology: A Longitudinal Study. Journal of the American Academy of Child and Adolescent Psychiatry 56, 321-328.e1.

Choi J, Jeong B, Rohan ML, Polcari AM, Teicher MH (2009). Preliminary evidence for white matter tract abnormalities in young adults exposed to parental verbal abuse. Biological Psychiatry 65, 227-234.

Contreras-Rodríguez O, Pujol J, Batalla I, Harrison BJ, Bosque J, Ibern-Regàs I, HernándezRibas R, Soriano-Mas C, Deus J, López-Solà M, Pifarré J, Menchón JM, Cardoner N (2014). Disrupted neural processing of emotional faces in psychopathy. Social Cognitive and Affective Neuroscience 9, 505-512.

Contreras-Rodríguez O, Pujol J, Batalla I, Harrison BJ, Soriano-Mas C, Deus J, López-Solà M, Macià D, Pera V, Hernández-Ribas R, Pifarré J, Menchón JM, Cardoner N (2015). Functional connectivity bias in the prefrontal cortex of psychopaths. Biological Psychiatry 78, $647-655$.

Cope LM, Ermer E, Nyalakanti PK, Calhoun VD, Kiehl KA (2014). Paralimbic gray matter reductions in incarcerated adolescent females with psychopathic traits. Journal of Abnormal Child Psychology 42, 659-668.

Cope LM, Vincent GM, Jobelius JL, Nyalakanti PK, Calhoun VD, Kiehl KA (2014). Psychopathic traits modulate brain responses to drug cues in incarcerated offenders. Frontiers in Human Neuroscience $\mathbf{8}, 87$.

Craig MC, Catani M, Deeley Q, Latham R, Daly E, Kanaan R, Picchioni M, McGuire PK, Fahy T, Murphy DG (2009). Altered connections on the road to psychopathy. Molecular Psychiatry 14, 946-953. 
da Cunha-Bang S, Hjordt LV, Perfalk E, Beliveau V, Bock C, Lehel S, Thomsen C, Sestoft D, Svarer C, Knudsen GM (2017). Serotonin 1B Receptor Binding Is Associated With Trait Anger and Level of Psychopathy in Violent Offenders. Biological Psychiatry 82, 267-274.

Darby RR, Horn A, Cushman F, Fox MD (2018). Lesion network localization of criminal behavior. Proceedings of the National Academy of Sciences of the USA. 2018 Jan 16;115(3):601-606.

De Brito SA, McCrory EJ, Mechelli A, Wilke M, Jones AP, Hodgins S, Viding E (2011). Small, but not perfectly formed: decreased white matter concentration in boys with psychopathic tendencies. Molecular Psychiatry 16, 476-477.

De Brito SA, Mechelli A, Wilke M, Laurens KR, Jones AP, Barker GJ, Hodgins S, Viding E (2009). Size matters: increased grey matter in boys with conduct problems and callousunemotional traits. Brain 132, 843-852.

de Oliveira-Souza R, Hare RD, Bramati IE, Garrido GJ, Azevedo Ignácio F, Tovar-Moll F, Moll J (2008). Psychopathy as a disorder of the moral brain: fronto-temporo-limbic grey matter reductions demonstrated by voxel-based morphometry. Neuroimage 40, 1202-1213.

Decety J, Chen C, Harenski C, Kiehl KA (2013a). An fMRI study of affective perspective taking in individuals with psychopathy: imagining another in pain does not evoke empathy. Frontiers in Human Neuroscience 7, 489.

Decety J, Chen C, Harenski CL, Kiehl KA (2015). Socioemotional processing of morally-laden behavior and their consequences on others in forensic psychopaths. Human Brain Mapping 36, 2015-2026.

Decety J, Skelly L, Yoder KJ, Kiehl KA (2014). Neural processing of dynamic emotional facial expressions in psychopaths. Social Neuroscience 9, 36-49.

Decety J, Skelly LR, Kiehl KA (2013b). Brain response to empathy-eliciting scenarios involving pain in incarcerated individuals with psychopathy. JAMA Psychiatry 70, 638-645.

Deeley Q, Daly E, Surguladze S, Tunstall N, Mezey G, Beer D, Ambikapathy A, Robertson D, Giampietro V, Brammer MJ, Clarke A, Dowsett J, Fahy T, Phillips ML, Murphy DG 
(2006). Facial emotion processing in criminal psychopathy. Preliminary functional magnetic resonance imaging study. The British Journal of Psychiatry 189, 533-539.

Diehl-Schmid J, Perneczky R, Koch J, Nedopil N, Kurz A (2013). Guilty by suspicion? Criminal behavior in frontotemporal lobar degeneration. Cognitive and Behavioral Neurology 26, 73-77.

Dolan MC, Deakin JF, Roberts N, Anderson IM (2002). Quantitative frontal and temporal structural MRI studies in personality-disordered offenders and control subjects. Psychiatry Research 116, 133-149.

Douaud G, Jbabdi S, Behrens TE, Menke RA, Gass A, Monsch AU, Rao A, Whitcher B, Kindlmann G, Matthews PM, Smith S (2011). DTI measures in crossing-fibre areas: increased diffusion anisotropy reveals early white matter alteration in MCI and mild Alzheimer's disease. Neuroimage 55: 880-890.

Ermer E, Cope LM, Nyalakanti PK, Calhoun VD, Kiehl KA (2012). Aberrant paralimbic gray matter in criminal psychopathy. Journal of Abnormal Psychology 121, 649-658.

Ermer E, Cope LM, Nyalakanti PK, Calhoun VD, Kiehl KA (2013). Aberrant paralimbic gray matter in incarcerated male adolescents with psychopathic traits. Journal of the American Academy of Child and Adolescent Psychiatry 52, 94-103.e3.

Fair DA, Cohen AL, Power JD, Dosenbach NU, Church JA, Miezin FM, Schlaggar BL, Petersen SE (2009). Functional brain networks develop from a "local to distributed" organization. PLOS Computational Biology 5: e1000381.

Fairchild G, Hagan CC, Walsh ND, Passamonti L, Calder AJ, Goodyer IM (2013). Brain structure abnormalities in adolescent girls with conduct disorder. Journal of Child Psychology and Psychiatry 54, 86-95.

Freeman SM, Clewett DV, Bennett CM, Kiehl KA, Gazzaniga MS, Miller MB (2015). The posteromedial region of the default mode network shows attenuated task-induced deactivation in psychopathic prisoners. Neuropsychology 29, 493-500.

Geurts DE, von Borries K, Volman I, Bulten BH, Cools R, Verkes RJ (2016). Neural connectivity during reward expectation dissociates psychopathic criminals from non-criminal individuals with 
high impulsive/antisocial psychopathic traits. Social Cognitive and Affective Neuroscience 11, $1326-1334$.

Glenn AL, Raine A, Schug RA (2009). The neural correlates of moral decision-making in psychopathy. Molecular Psychiatry 14, 5-6

Glenn AL, Raine A, Yaralian PS, Yang Y (2010b). Increased volume of the striatum in psychopathic individuals. Biological Psychiatry 67, 52-58.

Glenn AL, Yang Y, Raine A, Colletti P (2010a). No volumetric differences in the anterior cingulate of psychopathic individuals. Psychiatry Research 183, 140-143.

Greene JD, Sommerville RB, Nystrom LE, Darley JM, Cohen JD (2001). An fMRI investigation of emotional engagement in moral judgment. Science 293, 2105-2108.

Gregory S, Blair RJ, Ffytche D, Simmons A, Kumari V, Hodgins S, Blackwood N (2015). Punishment and psychopathy: a case-control functional MRI investigation of reinforcement learning in violent antisocial personality disordered men. Lancet Psychiatry 2,153-160.

Gregory S, ffytche D, Simmons A, Kumari V, Howard M, Hodgins S, Blackwood N (2012). The antisocial brain: psychopathy matters. Archives of General Psychiatry 69, 962-972.

Hare RD (2003). Hare Psychopathy Checklist-Revised (PCL-R), 2nd ed. Multi-Health Systems Inc: Toronto.

Harenski CL, Harenski KA, Kiehl KA (2014). Neural processing of moral violations among incarcerated adolescents with psychopathic traits. Developmental Cognitive Neuroscience 10, 181-189.

Harenski CL, Harenski KA, Shane MS, Kiehl KA (2010). Aberrant neural processing of moral violations in criminal psychopaths. Journal of Abnormal Psychology 119, 863-874.

\section{Harrison BJ, Pujol J, López-Solà M, Hernández-Ribas R, Deus J, Ortiz H, Soriano-Mas C,} Yücel M, Pantelis C, Cardoner N (2008). Consistency and functional specialization in the default mode brain network. Proceedings of the National Academy of Sciences of the USA 105, 9781-9786. 
Heany SJ, van Honk J, Stein DJ, Brooks SJ (2016). A quantitative and qualitative review of the effects of testosterone on the function and structure of the human social-emotional brain. Metabolic Brain Disease 31, 157-167.

Holz NE, Boecker R, Hohm E, Zohsel K, Buchmann AF, Blomeyer D, Barker G, Bokde AL, Bromberg U, Büchel C, Cattrell A, Conrod PJ, Desrivières S, Flor H, Frouin V, Gallinat J, Gowland P, Heinz A, Ittermann B, Paillère Martinot ML, Artiges E, Nees F, PapadopoulosOrfanos D, Poustka L, Smolka MN, Jurk S, Walter H, Whelan R, Schumann G, Althoff RR, Garavan H; IMAGEN Consortium (2015). The long-term impact of early life poverty on orbitofrontal cortex volume in adulthood: results from a prospective study over 25 years. Neuropsychopharmacology 40, 996-1004.

Hoppenbrouwers SS, Nazeri A, de Jesus DR, Stirpe T, Felsky D, Schutter DJ, Daskalakis ZJ, Voineskos AN (2013). White matter deficits in psychopathic offenders and correlation with factor structure. PLoS One 8:e72375.

Hyde LW, Byrd AL, Votruba-Drzal E, Hariri AR, Manuck SB (2014). Amygdala reactivity and negative emotionality: divergent correlates of antisocial personality and psychopathy traits in a community sample. Journal of Abnormal Psychology 123, 214-224.

Intrator J, Hare R, Stritzke P, Brichtswein K, Dorfman D, Harpur T, Bernstein D, Handelsman L, Schaefer C, Keilp J, Rosen J, Machac J (1997). A brain imaging (single photon emission computerized tomography) study of semantic and affective processing in psychopaths. Biological Psychiatry 42, 96-103.

Jeong W, Chung CK, Kim JS (2015). Episodic memory in aspects of large-scale brain networks. Frontiers in Human Neuroscience 9, 454.

Jiang W, Li G, Liu H, Shi F, Wang T, Shen C, Lee SW, Hu D, Wang W, Shen D (2016). Reduced cortical thickness and increased surface area in antisocial personality disorder. Neuroscience 337, $143-152$. 
Jiang W, Shi F, Liao J, Liu H, Wang T, Shen C, Hu D, Wang W, Shen D (2017a). Disrupted functional connectome in antisocial personality disorder. Brain Imaging and Behavior 11, 10711084.

Jiang W, Shi F, Liu H, Li G, Ding Z, Shen H, Lee SW, Hu D, Wang W, Shen D (2017b). Reduced white matter integrity in antisocial personality disorder: A diffusion tensor imaging study. Scientific Reports 7, 43002.

Jones DK, Knösche TR, Turner R (2013). White matter integrity, fiber count, and other fallacies: the do's and don'ts of diffusion MRI. Neuroimage 73: 239-254.

Juárez M, Kiehl KA, Calhoun VD (2013). Intrinsic limbic and paralimbic networks are associated with criminal psychopathy. Human Brain Mapping 34, 1921-1930.

Kiehl KA, Hoffman MB (2011). The criminal psychopath: history, neuroscience, treatment, and economics. Jurimetrics 51, 355-397.

Kiehl KA, Smith AM, Hare RD, Mendrek A, Forster BB, Brink J, Liddle PF (2001). Limbic abnormalities in affective processing by criminal psychopaths as revealed by functional magnetic resonance imaging. Biological Psychiatry 50, 677-684.

Koenigs M, Young L, Adolphs R, Tranel D, Cushman F, Hauser M, Damasio A (2007). Damage to the prefrontal cortex increases utilitarian moral judgements. Nature 446, 908-911.

Kolla NJ, Gregory S, Attard S, Blackwood N, Hodgins S (2014). Disentangling possible effects of childhood physical abuse on gray matter changes in violent offenders with psychopathy. Psychiatry Research 221, 123-126.

Kolla NJ, Matthews B, Wilson AA, Houle S, Bagby RM, Links P, Simpson AI, Hussain A, Meyer JH (2015). Lower monoamine oxidase-A total distribution volume in impulsive and violent male offenders with antisocial personality disorder and high psychopathic traits: An [(11)C] harmine positron emission tomography study. Neuropsychopharmacology 40, 2596-2603.

\section{Korponay C, Pujara M, Deming P, Philippi C, Decety J, Kosson DS, Kiehl KA, Koenigs M} (2017a). Impulsive-antisocial psychopathic traits linked to increased volume and functional connectivity within prefrontal cortex. Social Cognitive and Affective Neuroscience;12, 1169-1178. 


\section{Korponay C, Pujara M, Deming P, Philippi C, Decety J, Kosson DS, , Kiehl KA, Koenigs M} (2017b). Impulsive-antisocial dimension of psychopathy linked to enlargement and abnormal functional connectivity of the striatum. Biological Psychiatry: Cognitive Neuroscience and Neuroimaging 2, 149-157.

\section{Kumari V, Uddin S, Premkumar P, Young S, Gudjonsson GH, Raghuvanshi S, Barkataki I,} Sumich A, Taylor P, Das M (2014). Lower anterior cingulate volume in seriously violent men with antisocial personality disorder or schizophrenia and a history of childhood abuse. Australian and New Zealand Journal of Psychiatry 48, 153-161.

Laakso MP, Gunning-Dixon F, Vaurio O, Repo-Tiihonen E, Soininen H, Tiihonen J (2002). Prefrontal volumes in habitually violent subjects with antisocial personality disorder and type 2 alcoholism. Psychiatry Research 114, 95-102.

Laakso MP, Vaurio O, Koivisto E, Savolainen L, Eronen M, Aronen HJ, Hakola P, Repo E, Soininen H, Tiihonen J (2001). Psychopathy and the posterior hippocampus. Behavioural Brain Research 118, 187-193.

Lamsma J, Mackay C, Fazel S (2017). Structural brain correlates of interpersonal violence: Systematic review and voxel-based meta-analysis of neuroimaging studies. Psychiatry Res Neuroimaging 267, 69-73.

Lansing AE, Virk A, Notestine R, Plante WY, Fennema-Notestine C (2016). Cumulative trauma, adversity and grief symptoms associated with fronto-temporal regions in life-course persistent delinquent boys. Psychiatry Research 254, 92-102.

Larson CL, Baskin-Sommers AR, Stout DM, Balderston NL, Curtin JJ, Schultz DH, Kiehl KA, Newman JP (2013). The interplay of attention and emotion: top-down attention modulates amygdala activation in psychopathy. Cognitive, Affective, \& Behavioral Neuroscience 13, 757770.

Lebel C, Gee M, Camicioli R, Wieler M, Martin W, Beaulieu C (2012). Diffusion tensor imaging of white matter tract evolution over the lifespan. Neuroimage 60, 340-352. 
Leech R, Sharp DJ (2014). The role of the posterior cingulate cortex in cognition and disease. Brain 137, $12-32$.

Lilienfeld SO, Andrews BP (1996). Development and preliminary validation of a self-report measure of psychopathic personality traits in noncriminal populations. J Pers Assess 66, 488-524.

Ly M, Motzkin JC, Philippi CL, Kirk GR, Newman JP, Kiehl KA, Koenigs M (2012). Cortical thinning in psychopathy. The American Journal of Psychiatry 169, 743-749.

Mackey S, Chaarani B, Kan KJ, Spechler PA, Orr C, Banaschewski T, Barker G, Bokde AL, Bromberg U, Büchel C, Cattrell A, Conrod PJ, Desrivières S, Flor H, Frouin V, Gallinat J, Gowland P, Heinz A, Ittermann B, Paillère Martinot ML, Artiges E, Nees F, PapadopoulosOrfanos D, Poustka L, Smolka MN, Jurk S, Walter H, Whelan R, Schumann G, Althoff RR, Garavan H; IMAGEN Consortium (2017). Brain regions related to impulsivity mediate the effects of early adversity on antisocial behavior. Biological Psychiatry 82, 275-282.

Marsh AA, Cardinale EM (2014). When psychopathy impairs moral judgments: neural responses during judgments about causing fear. Social Cognitive and Affective Neuroscience 9, 3-11.

Matochik JA, Eldreth DA, Cadet JL, Bolla KI (2005). Altered brain tissue composition in heavy marijuana users. Drug and Alcohol Dependence 77, 23-30.

McKenzie IA, Ohayon D, Li H, de Faria JP, Emery B, Tohyama K, Richardson WD (2014). Motor skill learning requires active central myelination. Science 346, 318-322.

Meffert H, Gazzola V, den Boer JA, Bartels AA, Keysers C (2013). Reduced spontaneous but relatively normal deliberate vicarious representations in psychopathy. Brain 136, 2550-2562.

Mier D, Haddad L, Diers K, Dressing H, Meyer-Lindenberg A, Kirsch P (2014). Reduced embodied simulation in psychopathy. The World Journal of Biological Psychiatry 15, 479-487.

Moll J, de Oliveira-Souza R (2007). Moral judgments, emotions and the utilitarian brain. Trends in Cognitive Sciences 11, 319-221.

Moll J, de Oliveira-Souza R, Garrido GJ, Bramati IE, Caparelli-Daquer EM, Paiva ML, Zahn R, Grafman J (2007). The self as a moral agent: linking the neural bases of social agency and moral sensitivity. Social Neuroscience 2, 336-352. 
Moll J, De Oliveira-Souza R, Zahn R (2008). The neural basis of moral cognition: sentiments, concepts, and values. Annals of the New York Academy of Sciences 1124, 161-180.

Motzkin JC, Newman JP, Kiehl KA, Koenigs M (2011). Reduced prefrontal connectivity in psychopathy. Journal of Neuroscience 31, 17348-17357.

Müller JL, Gänssbauer S, Sommer M, Döhnel K, Weber T, Schmidt-Wilcke T, Hajak G. (2008). Gray matter changes in right superior temporal gyrus in criminal psychopaths. Evidence from voxel-based morphometry. Psychiatry Research 163, 213-222.

Müller JL, Sommer M, Wagner V, Lange K, Taschler H, Röder CH, Schuierer G, Klein HE, Hajak G (2003). Abnormalities in emotion processing within cortical and subcortical regions in criminal psychopaths: evidence from a functional magnetic resonance imaging study using pictures with emotional content. Biological Psychiatry 54, 152-162.

Narayan VM, Narr KL, Kumari V, Woods RP, Thompson PM, Toga AW, Sharma T (2007). Regional cortical thinning in subjects with violent antisocial personality disorder or schizophrenia. The American Journal of Psychiatry 164, 1418-1427.

Newman JP, Baskin-Sommers AR (2016). Smith and Lilienfeld's meta-analysis of the response modulation hypothesis: Important theoretical and quantitative clarifications. Psychological Bulletin 142, 1384-1393.

Newman JP, Curtin JJ, Bertsch JD, Baskin-Sommers AR (2010). Attention moderates the fearlessness of psychopathic offenders. Biological Psychiatry 67, 66-70.

Noordermeer SD, Luman M, Oosterlaan J (2016). A systematic review and meta-analysis of neuroimaging in Oppositional Defiant Disorder (ODD) and Conduct Disorder (CD) taking Attention-Deficit Hyperactivity Disorder (ADHD) into account. Neuropsychol Rev 26, 44-72.

Ou X, Andres A, Pivik RT, Cleves MA, Badger TM (2015). Brain gray and white matter differences in healthy normal weight and obese children. Journal of Magnetic Resonance Imaging 42, 1205-1213.

Patrick CJ (2014). Physiological correlates of psychopathy, antisocial personality disorder, habitual aggression, and violence. Curr Top Behav Neurosci 21,197-227. 
Patrick CJ, Fowles DC, Krueger RF (2009). Triarchic conceptualization of psychopathy: developmental origins of disinhibition, boldness, and meanness. Development and Psychopathology 21, 913-938.

Paus T, Collins DL, Evans AC, Leonard G, Pike B, Zijdenbos A (2001). Maturation of white matter in the human brain: a review of magnetic resonance studies. Brain Research Bulletin 54, 255-266.

Pera-Guardiola V, Contreras-Rodríguez O, Batalla I, Kosson D, Menchón JM, Pifarré J, Bosque J, Cardoner N, Soriano-Mas C (2016). Brain structural correlates of emotion recognition in psychopaths. PLoS One 11, e0149807.

Philippi CL, Pujara MS, Motzkin JC, Newman J, Kiehl KA, Koenigs M (2015). Altered restingstate functional connectivity in cortical networks in psychopathy. Journal of Neuroscience 35, 6068-6078.

Prehn K, Schlagenhauf F, Schulze L, Berger C, Vohs K, Fleischer M, Hauenstein K, Keiper P, Domes G, Herpertz SC (2013). Neural correlates of risk taking in violent criminal offenders characterized by emotional hypo- and hyper-reactivity. Social Neuroscience 136-147.

Pujara M, Motzkin JC, Newman JP, Kiehl KA, Koenigs M (2014). Neural correlates of reward and loss sensitivity in psychopathy. Social Cognitive and Affective Neuroscience 9, 794-801.

Pujol J, Batalla I, Contreras-Rodríguez O, Harrison BJ, Pera V, Hernández-Ribas R, Real E, Bosa L, Soriano-Mas C, Deus J, López-Solà M, Pifarré J, Menchón JM, Cardoner N (2012). Breakdown in the brain network subserving moral judgment in criminal psychopathy. Social Cognitive and Affective Neuroscience 7, 917-923.

Pujol J, Fenoll R, Forns J, Harrison BJ, Martínez-Vilavella G, Macià D, Alvarez-Pedrerol M, Blanco-Hinojo L, González-Ortiz S, Deus J, Sunyer J (2016). Video gaming in school children: How much is enough? Annals of Neurology 80, 424-33.

Pujol J, Martínez-Vilavella G, Macià D, Fenoll R, Alvarez-Pedrerol M, Rivas I, Forns J, BlancoHinojo L, Capellades J, Querol X, Deus J, Sunyer J (2016). Traffic pollution exposure is associated with altered brain connectivity in school children. Neuroimage 129, 175-184. 
Pujol J, Soriano-Mas C, Ortiz H, Sebastián-Gallés N, Losilla JM, Deus J (2006). Myelination of language-related areas in the developing brain. Neurology 66, 339-343.

Pujol J, Vendrell P, Junqué C, Martí-Vilalta JL, Capdevila A (1993). When does human brain development end? Evidence of corpus callosum growth up to adulthood. Annals of Neurology 34, $71-75$.

Raine A, Buchsbaum M, LaCasse L (1997). Brain abnormalities in murderers indicated by positron emission tomography. Biological Psychiatry 42, 495-508.

Raine A, Ishikawa SS, Arce E, Lencz T, Knuth KH, Bihrle S, LaCasse L, Colletti P (2004). Hippocampal structural asymmetry in unsuccessful psychopaths. Biological Psychiatry 55, 185191.

Raine A, Lee L, Yang Y, Colletti P (2010). Neurodevelopmental marker for limbic maldevelopment in antisocial personality disorder and psychopathy. The British Journal of Psychiatry 197, 186192.

Raine A, Lencz T, Bihrle S, LaCasse L, Colletti P (2000). Reduced prefrontal gray matter volume and reduced autonomic activity in antisocial personality disorder. Archives of General Psychiatry 57, 119-127.

Raine A, Lencz T, Taylor K, Hellige JB, Bihrle S, Lacasse L, Lee M, Ishikawa S, Colletti P (2003). Corpus callosum abnormalities in psychopathic antisocial individuals. Archives of General Psychiatry 60, 1134-1142.

Raine A, Yang Y (2006). Neural foundations to moral reasoning and antisocial behavior. Social Cognitive and Affective Neuroscience 1, 203-213.

Raine A, Yang Y, Narr KL, Toga AW (2011). Sex differences in orbitofrontal gray as a partial explanation for sex differences in antisocial personality. Molecular Psychiatry 16, 227-236.

\section{Rodman AM, Kastman E, Dorfman HM, Baskin-Sommers A, Kiehl KA, Newman JP, Buckholtz} JW (2016). Selective Mapping of Psychopathy and Externalizing to Dissociable Circuits for Inhibitory Self-Control. Clinical Psychological Science 4, 559-571. 
Rogers JC, De Brito SA (2016). Cortical and subcortical gray matter volume in youths with conduct problems: A Meta-analysis. JAMA Psychiatry 73, :64-72.

Saba L, Anzidei M, Raz E, Suri J, Piga M, Grassi R, Catalano C (2013). MR and CT of brain's cava. Journal of Neuroimaging 23, 326-335.

Sato JR, de Oliveira-Souza R, Thomaz CE, Basílio R, Bramati IE, Amaro E Jr, Tovar-Moll F, Hare RD, Moll J (2011). Identification of psychopathic individuals using pattern classification of MRI images. Social Neuroscience 6, 627-639.

Sato SM, Schulz KM, Sisk CL, Wood RI (2008). Adolescents and androgens, receptors and rewards. Hormones and Behavior 53, 647-658

Schneider F, Habel U, Kessler C, Posse S, Grodd W, Müller-Gärtner HW (2000). Functional imaging of conditioned aversive emotional responses in antisocial personality disorder. Neuropsychobiology 42, 192-201.

Schultz DH, Balderston NL, Baskin-Sommers AR, Larson CL, Helmstetter FJ (2016). Psychopaths Show Enhanced Amygdala Activation during Fear Conditioning. Frontiers in Psychology 7, 348.

Sethi A, Gregory S, Dell'Acqua F, Periche Thomas E, Simmons A, Murphy DG, Hodgins S, Blackwood NJ, Craig MC (2015). Emotional detachment in psychopathy: Involvement of dorsal default-mode connections. Cortex 62, 11-19.

Sherman LE, Rudie JD, Pfeifer JH, Masten CL, McNealy K, Dapretto M (2014). Development of the default mode and central executive networks across early adolescence: a longitudinal study. Developmental Cognitive Neuroscience 10, 148-159.

Simpson EH and Balsam PD (2016). Behavioral neuroscience of motivation. Switzerland: Springer International Publishing,

Sitaram R, Caria A, Veit R, Gaber T, Ruiz S, Birbaumer N (2014). Volitional control of the anterior insula in criminal psychopaths using real-time fMRI neurofeedback: a pilot study. Frontiers in Behavioral Neuroscience 8, 344. 
Soderstrom H, Hultin L, Tullberg M, Wikkelso C, Ekholm S, Forsman A (2002). Reduced frontotemporal perfusion in psychopathic personality. Psychiatry Research 114, 81-94.

Sommer M, Sodian B, Döhnel K, Schwerdtner J, Meinhardt J, Hajak G (2010). In psychopathic patients emotion attribution modulates activity in outcome-related brain areas. Psychiatry Research 182, 88-95.

Soriano-Mas C, Hernández-Ribas R, Pujol J, Urretavizcaya M, Deus J, Harrison BJ, Ortiz H, López-Solà M, Menchón JM, Cardoner N (2011). Cross-sectional and longitudinal assessment of structural brain alterations in melancholic depression. Biological Psychiatry 69, 318-325.

Sundram F, Deeley Q, Sarkar S, Daly E, Latham R, Craig M, Raczek M, Fahy T, Picchioni M; UK AIMS Network, Barker GJ, Murphy DG (2012). White matter microstructural abnormalities in the frontal lobe of adults with antisocial personality disorder. Cortex 48, 216229.

Tang Y, Long J, Wang W, Liao J, Xie H, Zhao G, Zhang H (2016). Aberrant functional brain connectome in people with antisocial personality disorder. Scientific Reports 6, 26209.

Tiihonen J, Rossi R, Laakso MP, Hodgins S, Testa C, Perez J, Repo-Tiihonen E, Vaurio O, Soininen H, Aronen HJ, Könönen M, Thompson PM, Frisoni GB (2008). Brain anatomy of persistent violent offenders: more rather than less. Psychiatry Research 163, 201-212.

Toivonen P, Könönen M, Niskanen E, Vaurio O, Repo-Tiihonen E, Seppänen A, Aronen HJ, Vanninen R, Tiihonen J, Laakso MP (2013). Cavum septum pellucidum and psychopathy. The British Journal of Psychiatry 203, 152-153.

Veit R, Flor H, Erb M, Hermann C, Lotze M, Grodd W, Birbaumer N (2002). Brain circuits involved in emotional learning in antisocial behavior and social phobia in humans. Neuroscience Letters 328, 233-236.

Veit R, Lotze M, Sewing S, Missenhardt H, Gaber T, Birbaumer N (2010). Aberrant social and cerebral responding in a competitive reaction time paradigm in criminal psychopaths. Neuroimage 49, 3365-3372. 
Venables NC, Hall JR, Patrick CJ (2014). Differentiating psychopathy from antisocial personality disorder: a triarchic model perspective. Psychol Med 44, 1005-1013.

Veroude K, von Rhein D, Chauvin RJ, van Dongen EV, Mennes MJ, Franke B, Heslenfeld DJ, Oosterlaan J, Hartman CA, Hoekstra PJ, Glennon JC, Buitelaar JK (2016). The link between callous-unemotional traits and neural mechanisms of reward processing: An fMRI study. Psychiatry Research 255, 75-80.

Volkow ND, Tancredi LR, Grant C, Gillespie H, Valentine A, Mullani N, Wang GJ, Hollister L (1995). Brain glucose metabolism in violent psychiatric patients: a preliminary study. Psychiatry Research 61, 243-253.

Volman I, von Borries AK, Bulten BH, Verkes RJ, Toni I, Roelofs K (2016). Testosterone modulates altered prefrontal control of emotional actions in psychopathic offenders. eNeuro 3, pii, ENEURO.0107-15.2016.

Waller R, Dotterer HL, Murray L, Maxwell AM, Hyde LW (2017). White-matter tract abnormalities and antisocial behavior: A systematic review of diffusion tensor imaging studies across development. Neuroimage Clinical 14, 201-215.

Walters GD, Ermer E, Knight RA, Kiehl KA (2015). Paralimbic biomarkers in taxometric analyses of psychopathy: does changing the indicators change the conclusion? Personality Disorders 6, 41 52.

White SF, Brislin S, Sinclair S, Fowler KA, Pope K, Blair RJ (2013). The relationship between large cavum septum pellucidum and antisocial behavior, callous-unemotional traits and psychopathy in adolescents. Journal of Child Psychology and Psychiatry 54, 575-581.

\section{Wolf RC, Pujara MS, Motzkin JC, Newman JP, Kiehl KA, Decety J, Kosson DS, Koenigs M} (2015). Interpersonal traits of psychopathy linked to reduced integrity of the uncinate fasciculus. Human Brain Mapping 36, 4202-4209.

Yakovlev PI, LeCours AR (1967): The myelogenetic cycles of regional maturation of the brain. In: Minkowski A, editor. Regional Development of the Brain in Early Life. Oxford: Blackwell. 3-70. 
Yang Y, Raine A (2009). Prefrontal structural and functional brain imaging findings in antisocial, violent, and psychopathic individuals: a meta-analysis. Psychiatry Res 174, 81-88.

Yang Y, Raine A, Colletti P, Toga AW, Narr KL (2009a). Abnormal temporal and prefrontal cortical gray matter thinning in psychopaths. Molecular Psychiatry 14, 561-562.

Yang Y, Raine A, Colletti P, Toga AW, Narr KL (2010). Morphological alterations in the prefrontal cortex and the amygdala in unsuccessful psychopaths. Journal of Abnormal Psychology 119, 546-554.

Yang Y, Raine A, Joshi AA, Joshi S, Chang YT, Schug RA, Wheland D, Leahy R, Narr KL (2012). Frontal information flow and connectivity in psychopathy. The British Journal of Psychiatry 201, 408-409.

Yang Y, Raine A, Lencz T, Bihrle S, LaCasse L, Colletti P (2005). Volume reduction in prefrontal gray matter in unsuccessful criminal psychopaths. Biological Psychiatry 57, 1103-1108.

Yang Y, Raine A, Lencz T, Bihrle S, Lacasse L, Colletti P (2005). Prefrontal white matter in pathological liars. The British Journal of Psychiatry 187, 320-325.

Yang Y, Raine A, Narr KL, Colletti P, Toga AW (2009b). Localization of deformations within the amygdala in individuals with psychopathy. Archives of General Psychiatry 66, 986-994.

Yildirim BO, Derksen JJ (2012). A review on the relationship between testosterone and life-course persistent antisocial behavior. Psychiatry Research 200, 984-1010.

Yoder KJ, Harenski C, Kiehl KA, Decety J (2015). Neural networks underlying implicit and explicit moral evaluations in psychopathy. Translational Psychiatry 5, e625. 


\section{Figures}

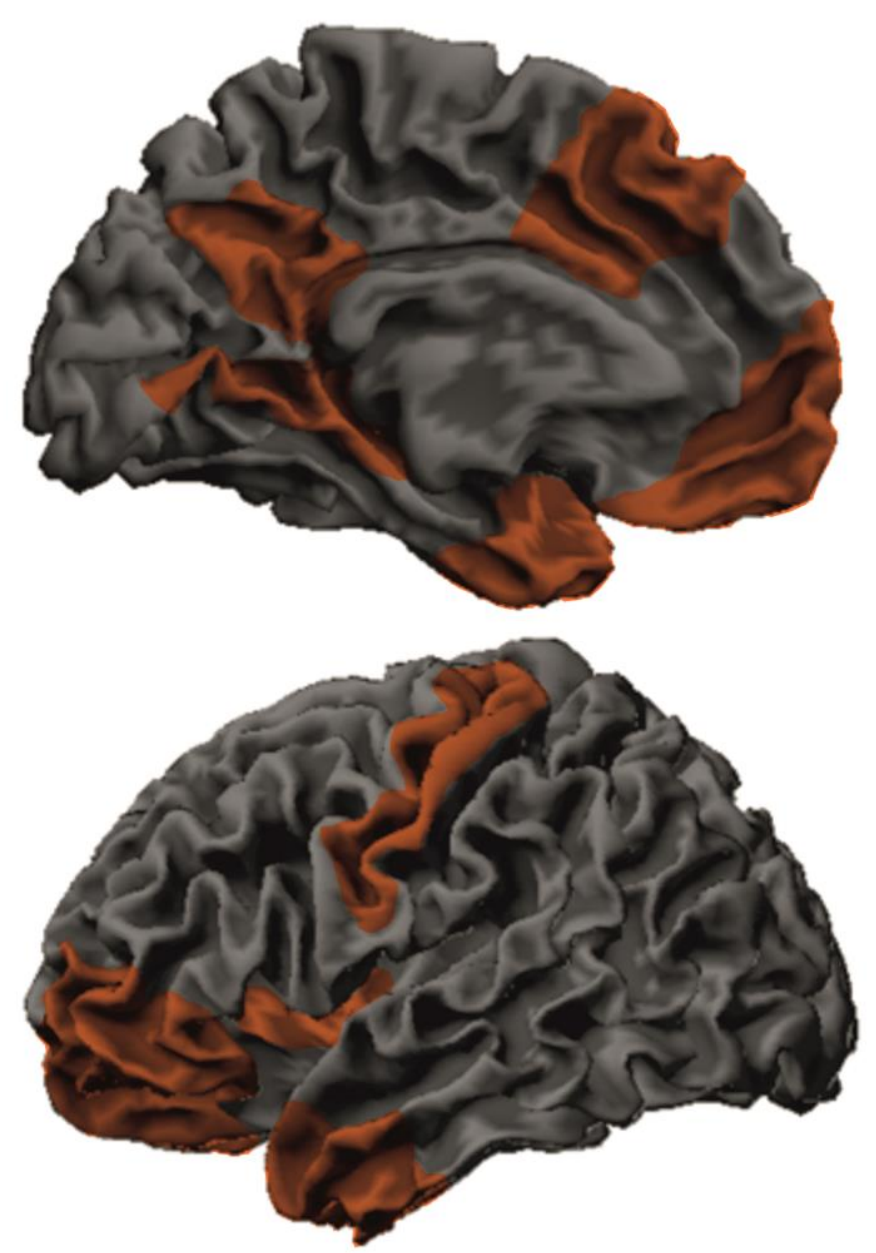

Figure 1. Schematic representation of brain regions showing the most consistent gray matter volume reduction in primary psychopathy according to the literature. 


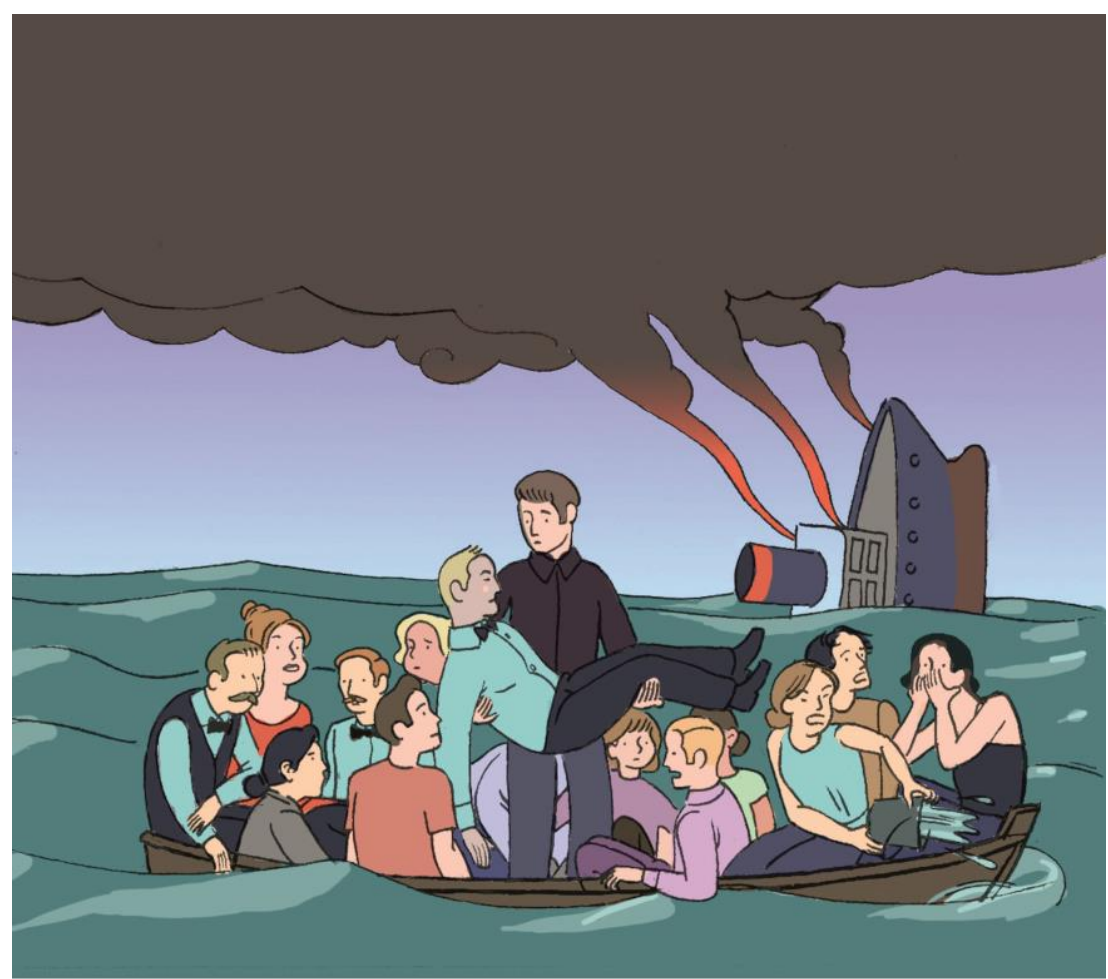

On board is an injured man that will probably not survive. If you throw this man overboard he will certainly die, but the boat will stay afloat and the others may survive. If you do not do so, the boat will probably sink and all of them will die.

\section{Would you throw the injured man overboard?}

Figure 2. Representation of a typical moral dilemma used in functional MRI experiments in psychopaths. Adapted, with permission, from Pujol et al. (2012). 


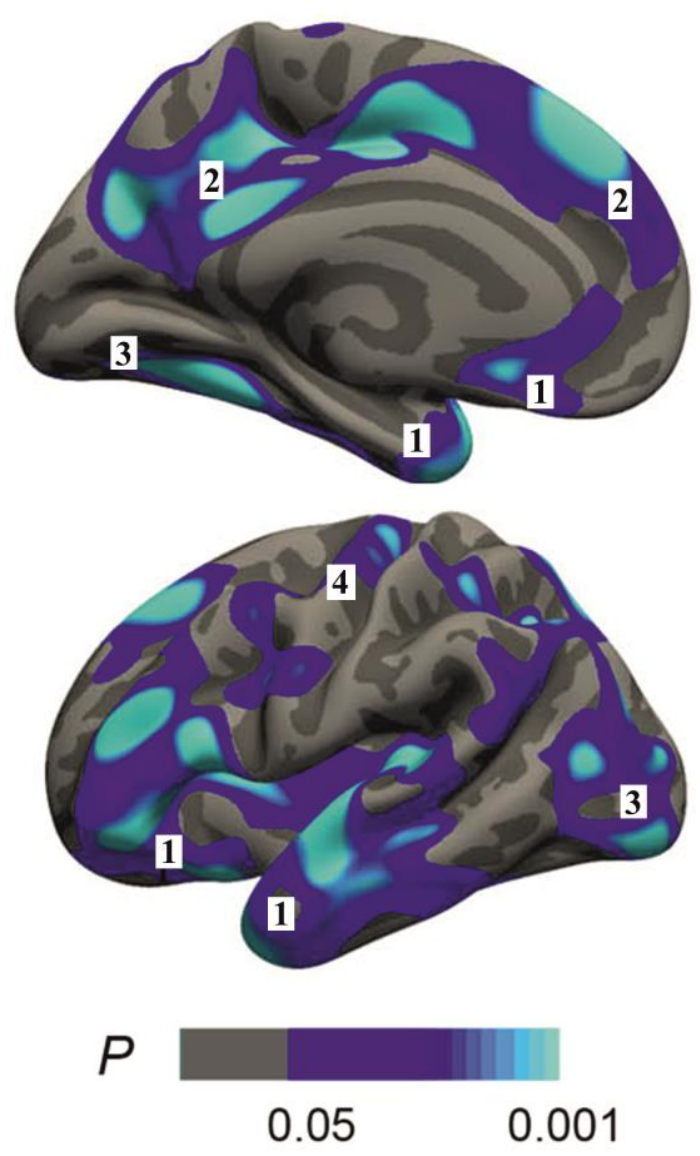

Figure 3. Regions showing reduced cortical thickness in users exceeding 10 years of anabolicandrogenic steroid exposure compared with control subjects. Adapted, with permission, from Bjørnebekk et al. (2017). Note the notable regional coincidence with the areas showing the most consistent volume reduction in psychopaths illustrated in Figure 1. The largest coincidences are present in the ventral temporal-frontal system (1) and the dorsal-medial system (2), but cortical reductions are also present in visual (3) and motor cortices (4). 
Table 1. Gray matter reduction in psychopathy

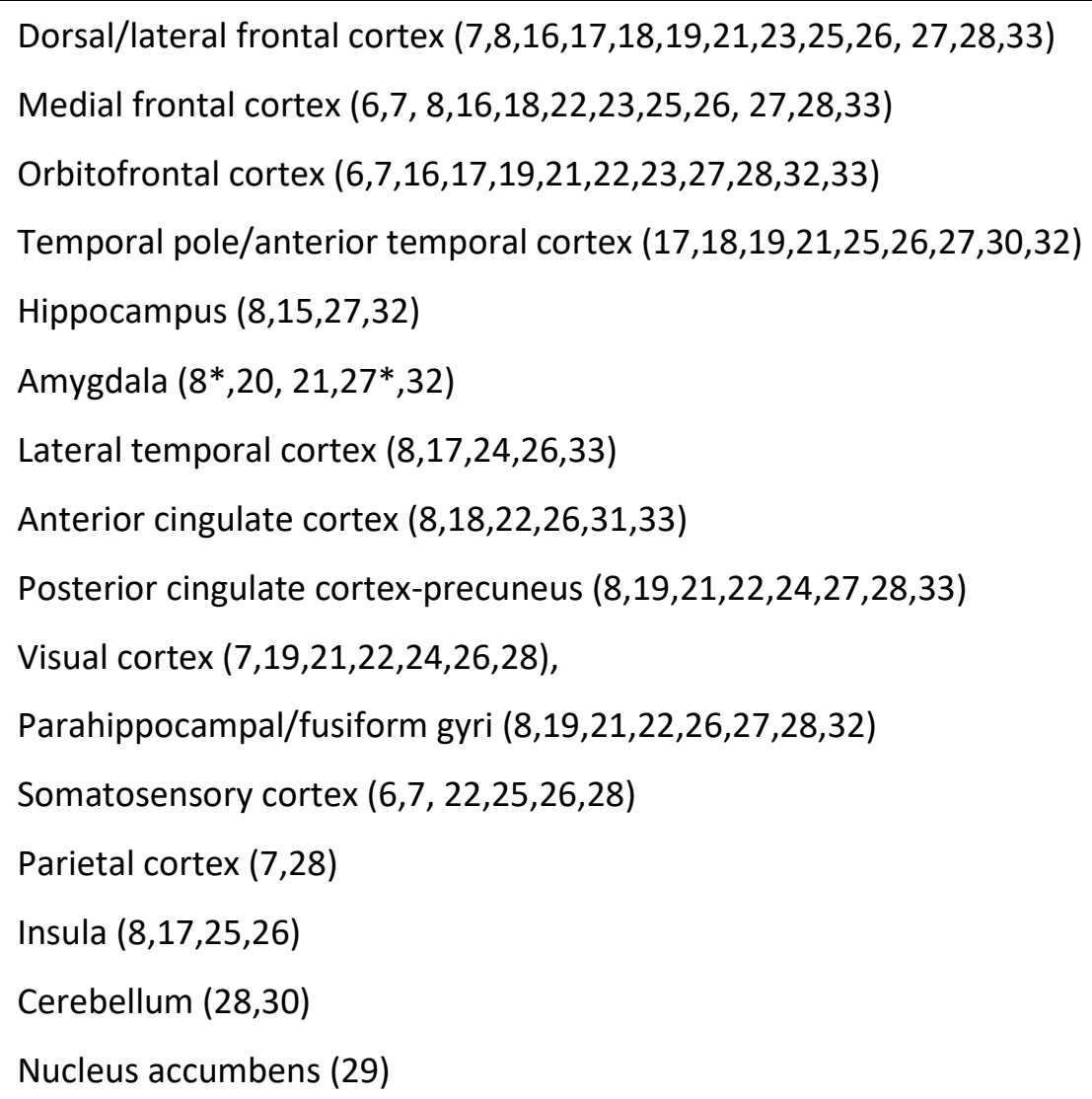

